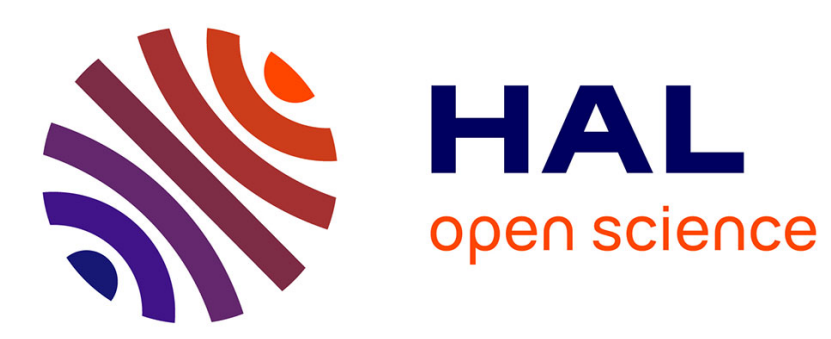

\title{
Reliability-based analysis of strip footings subjected to an inclined or an eccentric loading
}

Dalia S. Youssef Abdel Massih, Abdul-Hamid Soubra, Nut Mao

\section{To cite this version:}

Dalia S. Youssef Abdel Massih, Abdul-Hamid Soubra, Nut Mao. Reliability-based analysis of strip footings subjected to an inclined or an eccentric loading. GeoFlorida, American Society of Civil Engineers, 2010, Orlando, United States. 10.1061/41095(365)216 . hal-01008823

\section{HAL Id: hal-01008823 \\ https://hal.science/hal-01008823}

Submitted on 6 Apr 2018

HAL is a multi-disciplinary open access archive for the deposit and dissemination of scientific research documents, whether they are published or not. The documents may come from teaching and research institutions in France or abroad, or from public or private research centers.
L'archive ouverte pluridisciplinaire HAL, est destinée au dépôt et à la diffusion de documents scientifiques de niveau recherche, publiés ou non, émanant des établissements d'enseignement et de recherche français ou étrangers, des laboratoires publics ou privés. 


\title{
Reliability-based analysis of strip footings subjected to an inclined or an eccentric loading
}

\author{
Dalia S. Youssef Abdel Massih ${ }^{1}$, Abdul-Hamid Soubra $^{2}$, M.ASCE and Nut Mao ${ }^{3}$ \\ ${ }^{1}$ Researcher, CNRS, Bhanes, Lebanon; Dalia@cnrs.edu.lb \\ ${ }^{2}$ Professor, Corresponding author, University of Nantes, Bd. de l'université, BP 152, 44603 Saint- \\ Nazaire cedex, France; Abed.Soubra@univ-nantes.fr \\ ${ }^{3} \mathrm{PhD}$ student, University of Nantes, Bd. de l'université, BP 152, 44603 Saint-Nazaire cedex, France; \\ Nut.Mao@univ-nantes.fr
}

\begin{abstract}
This paper presents a reliability-based approach at the ultimate limit state for the analysis of a shallow strip footing resting on a frictional and cohesive soil and subjected to an inclined or an eccentric loading. Only the soil shear strength parameters are modeled as random variables. The Hasofer-Lind reliability index is used for the computation of the footing reliability. The response surface methodology is employed for the assessment of the reliability index. The performance function adopted in the analysis makes use of the safety factor defined with respect to the soil shear strength parameters $c$ and $\tan \varphi$. For both cases of an inclined and an eccentric loading, it was shown that there is a load inclination and a load eccentricity for which the two failure modes involved by the loading case are not predominant. It was also shown that the hypothesis of negative correlation between random variables increases the reliability of the footing and that the failure probability is very sensitive to the variation of the angle of internal friction compared to that of the cohesion.
\end{abstract}

\section{INTRODUCTION}

Uncertainties are abundant in civil engineering systems. For the sake of simplicity, geotechnical engineers have traditionally used approximate design approaches based on the concept of the safety factor. A reliability-based analysis is a more rigorous approach since it considers the uncertainty of each parameter via its probability distribution. Previous investigations on the reliability analysis of foundations focused on shallow strip footings subjected to a symmetric vertical load and considered either the ultimate (ULS) or the serviceability (SLS) limit state (Bauer and Pula 2000; Cherubini 2000; Low and Phoon 2002; Fenton and Griffiths 2003; Popescu et al. 2005; Youssef Abdel Massih et al. 2008; Soubra and Youssef Abdel Massih 2009). In this paper, a reliability-based approach for the analysis of a shallow strip footing resting on a frictional and cohesive soil and subjected to an inclined (V, $\mathrm{H})$ or an eccentric $(\mathrm{V}, \mathrm{M})$ loading is presented. The aim of the paper is to determine the reliability index at ULS due not only to the soil punching failure mode but also due to footing sliding or overturning which may occur due to the inclination or the eccentricity of the applied load respectively. The random variables considered in the analysis are the soil shear strength parameters $c$ and $\varphi$. The Hasofer-Lind reliability index is adopted for the computation of the foundation reliability. The response surface methodology is used to find an approximation of the analytically-unknown performance function and the corresponding reliability index. The performance 
function makes use of the safety factor $F_{s}$ defined with respect to the soil shear strength parameters $c$ and $\tan \varphi$. This factor is equal to the ratio between the maximal shear stress and the mobilized one.

The structure of this paper is as follows: the first section introduces the basic concepts of reliability used in the paper. The second one presents the reliability analysis of a strip footing. The next section discusses the deterministic and reliabilitybased results. It is followed by a conclusion.

\section{RELIABILITY THEORY}

Two different measures are commonly used in literature to describe the reliability of a structure: The reliability index and the failure probability. The widely used reliability index is the one defined by Hasofer and Lind (1974). Its matrix formulation is given by:

$$
\beta_{H L}=\min _{x \in F} \sqrt{(x-\mu)^{T} C^{-1}(x-\mu)}
$$

in which $\mathrm{x}$ is the vector representing the $\mathrm{n}$ random variables, $\mu$ is the vector of their mean values, $\mathrm{C}$ is their covariance matrix and $\mathrm{F}$ is the failure region. The minimization of equation (1) is subjected to the constraint $\mathrm{G}(\mathrm{x}) \leq 0$ where the limit state surface $\mathrm{G}(\mathrm{x})=0$ separates the $\mathrm{n}$-dimensional domain of random variables into two regions: A failure region $F$ represented by $\mathrm{G}(\mathrm{x}) \leq 0$ and a safe region given by $\mathrm{G}(\mathrm{x})>0$ where $\mathrm{G}(\mathrm{x})$ denotes the performance function. From the First Order Reliability Method (FORM) and the Hasofer-Lind reliability index $\beta_{\mathrm{HL}}$, one can approximate the failure probability $\mathrm{P}_{\mathrm{f}}$ as follows:

$$
\mathrm{P}_{\mathrm{f}}=\Phi\left(-\beta_{\mathrm{HL}}\right)
$$

where $\Phi($.$) is the cumulative distribution function (CDF) of a standard normal$ variable. Since the response of the model is obtained in the present paper by numerical simulations using FLAC $^{3 \mathrm{D}}$ software, its closed-form solution is not available. Consequently, the performance function that makes use of this response is also unavailable. Thus, the determination of the reliability index is not straightforward. In this case, an algorithm based on the Response Surface Methodology (RSM) proposed by Tandjiria et al. (2000) and used later by Youssef Abdel Massih and Soubra (2008) is employed herein. It allows one to get the closedform solution of the model response $\mathrm{Y}(\mathrm{x})$ [and consequently the performance function $\mathrm{G}(\mathrm{x})$ ] by approximation via iterations. This algorithm is simple in implementation and gives rapid convergence. It considers that the expression of the unknown system response may be approximated by the following second order polynomial:

$$
\mathrm{Y}(\mathrm{x})=\mathrm{a}_{0}+\sum_{\mathrm{i}=1}^{\mathrm{n}} \mathrm{a}_{\mathrm{i}} \mathrm{x}_{\mathrm{i}}+\sum_{\mathrm{i}=1}^{\mathrm{n}} \mathrm{a}_{\mathrm{b}} \mathrm{x}_{\mathrm{i}}^{2}
$$

where $x_{i}$ are the random variables, $\mathrm{n}$ is the number of the random variables and $\left(a_{i}, b_{i}\right)$ are unknown coefficients to be determined. The random variables are 
characterized by their mean values $\mu_{\mathrm{i}}$ and their standard deviation values $\sigma_{\mathrm{i}}$. The steps of the algorithm are as follows:

1. Evaluate the performance function $\mathrm{G}(\mathrm{x})$ at the mean value point $\mu$ and the $2 \mathrm{n}$ points each at $\mu \pm k \sigma$ where $k$ is equal to one in the present paper;

2. The above $2 n+1$ values of $\mathrm{G}(\mathrm{x})$ can be used to solve Eq. 3 for the coefficients $\left(a_{i}, b_{i}\right)$. This obtains a tentative response surface function;

3. Solve Eq. 1 subjected to the constraint that the tentative response surface function of step 2 is equal to zero. This obtains a tentative design point and a corresponding tentative reliability index $\beta_{\mathrm{HL}}$;

4. Repeat steps 1 to 3 until convergence. Each time step 1 is repeated, the sampled points are centered at the new tentative design point of step 3 .

\section{RELIABILITY ANALYSIS OF A STRIP FOOTING}

The aim of this paper is to perform a reliability analysis of a shallow strip footing resting on a $c-\varphi$ soil and subjected to an inclined $(\mathrm{V}, \mathrm{H})$ or an eccentric $(\mathrm{V}$, M) loading. After introducing the deterministic numerical model based on the finite difference code $\mathrm{FLAC}^{3 \mathrm{D}}$, we present the performance function used in the reliability analysis and the numerical implementation of RSM.

\section{Deterministic numerical simulations}

This section focuses on the determination of the deterministic limit loads of a perfectly rough rigid strip footing, of breadth $\mathrm{B}=2 \mathrm{~m}$, resting on a $\mathrm{c}-\varphi$ soil and subjected to an inclined or an eccentric loading. The three-dimensional finite difference code FLAC $^{3 \mathrm{D}}$ based on a Lagrangian explicit calculation scheme and a mixed discretization zoning technique is used for the numerical simulations.

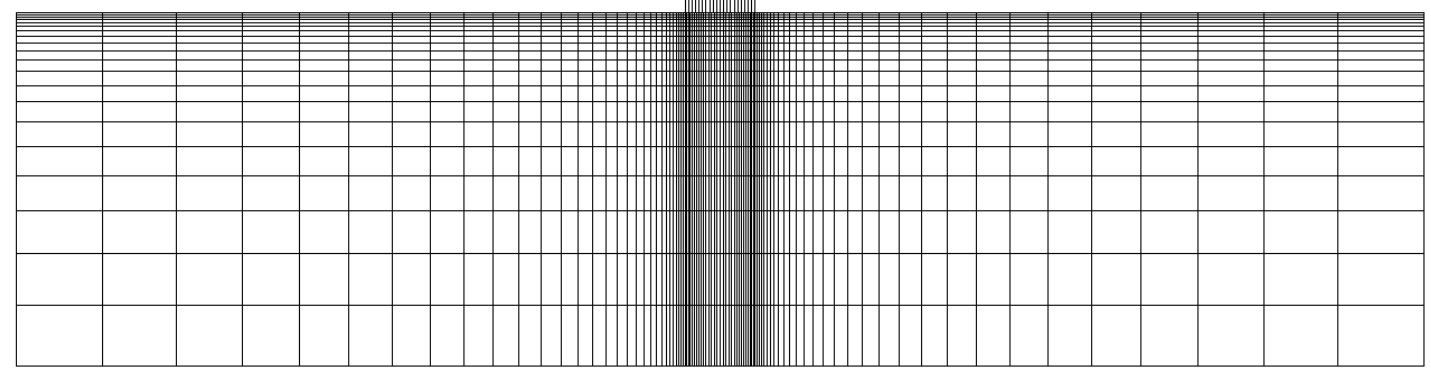

Figure 1: Soil domain and mesh used in FLAC $^{3 \mathrm{D}}$

Figure (1) illustrates the soil domain of width 20B and depth 5B considered in the analysis. The bottom and both vertical boundaries are far enough from the footing and they do not disturb the soil mass in motion (i.e. velocity field) for all the soil configurations studied in this paper. A symmetrical but non uniform mesh composed of 1820 zones is considered in the analysis. A conventional elastic-perfectly plastic model based on Mohr-Coulomb failure criterion is used to represent the soil. The illustrative values of the soil elastic properties used are the shear modulus $\mathrm{G}=100$ $\mathrm{MPa}$ and the bulk modulus $\mathrm{K}=133 \mathrm{MPa}$ (i.e $\mathrm{E}=240 \mathrm{MPa}$ and $v=0.2$ ). Also, the illustrative values of the soil shear strength parameters used in the analysis are: $\varphi=30^{\circ}, \psi=(2 / 3) \varphi$ and $\mathrm{c}=20 \mathrm{kPa}$, where $\Psi$ is the soil dilation angle. The soil unit 
weight was taken equal to $18 \mathrm{kN} / \mathrm{m}^{3}$. In all the cases studied in this paper, the presence of water table is not considered. The strip footing of width equal to $2 \mathrm{~m}$ and depth $0.5 \mathrm{~m}$ is simulated by a weightless elastic material. It is divided horizontally into twenty zones. The footing elastic properties used are the Young's modulus E=25 $\mathrm{GPa}$ and the Poisson's ratio $v=0.4$ which ensure the rigid behavior of the footing compared to that of the soil. The footing is connected to the soil via interface elements that follow Coulomb criterion. In order to simulate a perfectly rough soilfooting interface, the shear strength parameters considered for the interface are those of the soil. Note that no tension is considered at the soil footing interface. Normal stiffness $K_{n}=1 \mathrm{GPa} / \mathrm{m}$ and shear stiffness $\mathrm{K}_{\mathrm{s}}=1 \mathrm{GPa} / \mathrm{m}$ are assigned to this interface. It was found that these parameters do not have a major influence on the failure loads. The numerical simulation procedure used for the computation of each point of the $(\mathrm{H}$, $\mathrm{V})$ and $(\mathrm{M}, \mathrm{V})$ failure envelopes is presented in Youssef Abdel Massih and Soubra (2007) and not repeated herein.

\section{Performance function and numerical implementation of RSM}

The performance function adopted in the analysis makes use of the safety factor $F_{\mathrm{s}}$ defined with respect to the soil shear strength parameters $\mathrm{c}$ and $\tan \varphi$ :

$$
\mathrm{G}=\mathrm{F}_{\mathrm{s}}-1
$$

The procedure of calculating the system response $\mathrm{F}_{\mathrm{s}}$ for an inclined or an eccentric loading is based on the strength reduction method implemented into FLAC ${ }^{3 \mathrm{D}}$. It should be emphasized here that the safety factor $F_{\mathrm{s}}$ is assumed to be similar not only for both $c$ and $\tan \varphi$ of the soil, but also for those of the interface. This is not the case of Load and Resistance Factor Design (LRFD) where different partial safety factors are affected to the different parameters. Since the closed-form solution of $F_{s}$ is not available, RSM algorithm by Tandjiria et al. (2000) is used herein. Thus, equation (3) will be used to approximate the system response $\mathrm{F}_{\mathrm{s}}$ and consequently the performance function G. As described before, the determination of the Hasofer-Lind reliability index requires (i) the determination of the coefficients $\left(a_{i}, b_{i}\right)$ of the tentative response surface via the resolution of equation (3) for the 5 sampled points (since $\mathrm{n}=2$ ) and (ii) the minimization of $\beta_{\mathrm{HL}}$ subjected to the constraint that the tentative response surface function is equal to zero. These two operations constitute a single iteration and were done using the optimization toolbox available in Matlab 7.0 software. Several iterations were performed until convergence of $\beta_{\mathrm{HL}}$. Convergence is considered to be reached when a difference smaller than 0.01 between two successive reliability indexes is obtained. Since the determination of the performance function at the 5 sampled points was performed using FLAC $^{3 \mathrm{D}}$ software, the results of these computations constitute input parameters for the determination of the coefficients $\left(a_{i}, b_{i}\right)$ of the tentative response surface using Matlab 7.0. The value of the design point determined by the minimization procedure in Matlab 7.0 is also an input parameter for the determination of the performance function at the new 5 sampled points in FLAC ${ }^{3 \mathrm{D}}$. Therefore, an exchange of data between FLAC ${ }^{3 \mathrm{D}}$ and Matlab 7.0 was necessary to enable an automatic resolution of the iterative algorithm for the determination of the Hasofer-Lind reliability index. This was performed using 
text files and FISH commands of FLAC ${ }^{3 \mathrm{D}}$. Note that FISH is a programming language embedded within FLAC $^{3 \mathrm{D}}$ that enables the user to define new variables and functions. These functions may be used to extend FLAC ${ }^{3 \mathrm{D}}$ usefulness or add userdefined features.

\section{NUMERICAL RESULTS}

In this section, we will present the numerical deterministic and probabilistic results. For most soils, the mean value of the effective angle of internal friction is typically between $20^{\circ}$ and $40^{\circ}$. Within this range, the corresponding coefficient of variation COV as proposed by Phoon and Kulhawy (1999) is essentially between 5\% and $15 \%$. For the effective cohesion, its COV varies between $10 \%$ and $70 \%$ (Cherubini 2000). For the coefficient of correlation, the results of Wolff (1985) have shown that a negative correlation of $\rho_{\mathrm{c}, \varphi}=-0.47$, exists between the effective cohesion $\mathrm{c}$ and the effective angle of internal friction $\varphi$. The results of Yuceman et al. (1973) $\left(-0.49 \leq \rho_{\mathrm{c}, \varphi} \leq-0.24\right)$, Lumb (1970) $\left(-0.70 \leq \rho_{\mathrm{c}, \varphi} \leq-0.37\right)$ and Cherubini (2000) $\left(\rho_{c, \varphi}=-0.61\right)$ are among the ones cited in the literature. The illustrative values used for the statistical moments of the shear strength parameters and their coefficient of correlation $\rho_{c, \varphi}$ are given as follows: $\mu_{c}=20 \mathrm{kPa}, \mu_{\varphi}=30^{\circ}$, $\mathrm{COV}_{\mathrm{c}}=20 \%, \mathrm{COV}_{\varphi}=10 \%$ and $\rho_{\mathrm{c}, \varphi}=-0.5$. For the probability distribution of the random variables, two cases are studied. In the first case referred to as normal variables, $c$ and $\varphi$ are considered as normal variables. In the second case referred to as non-normal variables, $c$ is assumed to be log-normally distributed while $\varphi$ is assumed to be bounded and a beta distribution is used (e.g. Fenton and Griffiths, 2003). The parameters of the beta distribution are determined from the mean value and standard deviation of $\varphi$. For both cases, either negatively correlated (with $\rho_{c, \varphi}=-$ 0.5 ) or uncorrelated shear strength parameters are considered. Notice that in all the probabilistic analyses performed in this paper, c, $\varphi$ and $\psi$ of the soil-footing interface are assumed equal to those of the soil. This means that they were indirectly considered as random variables having the same randomness as the corresponding soil parameters.

\section{Inclined loading case}

The deterministic results of an inclined loading case are presented in the form of an interaction diagram $(\mathrm{H}, \mathrm{V})$ (which corresponds to $\mathrm{F}_{\mathrm{s}}=1$ ) using the mean values of the soil shear strength parameters $\mathrm{c}$ and $\varphi$ (figure (2)). The sliding of the footing occurs for high load inclinations (i.e. for small values of the vertical load) and soil punching is developed for small values of the load inclination (i.e. for high values of the vertical load).

Figure (3) presents the factor of safety versus the vertical load component $\mathrm{V}$ for the three different values of the horizontal load component $H$ shown in figure (2). The three curves exhibit a maximum. From the numerical results, it was observed that all the three maximums correspond to the same ratio $\mathrm{H} / \mathrm{V}$ (i.e. to the same load inclination). In order to interpret this result, the factor of safety is plotted versus the 
load inclination $(\alpha)$ in figure (4). From this figure, one can observe that the factor of safety reaches its maximal value at the same load inclination $\left(\alpha=18.43^{\circ}\right.$ in the present case) for the different values of $\mathrm{H}$. This means that for a given soil and for a given horizontal load component, the maximal soil resistance expressed in terms of the safety factor is obtained at a given value of the vertical load component for which $\mathrm{H} / \mathrm{V}=$ constant. This observation will be emphasized in the following paragraph when dealing with failure probabilities.

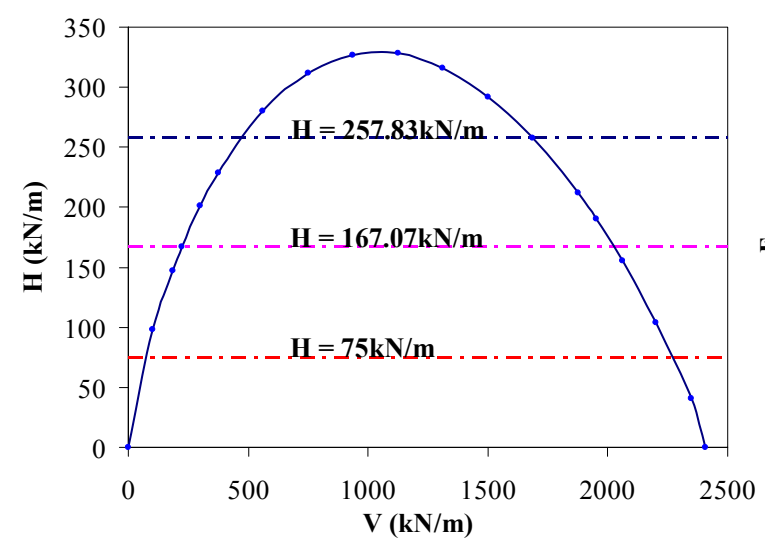

Figure 2: Interaction diagram $(\mathrm{H}, \mathrm{V})$

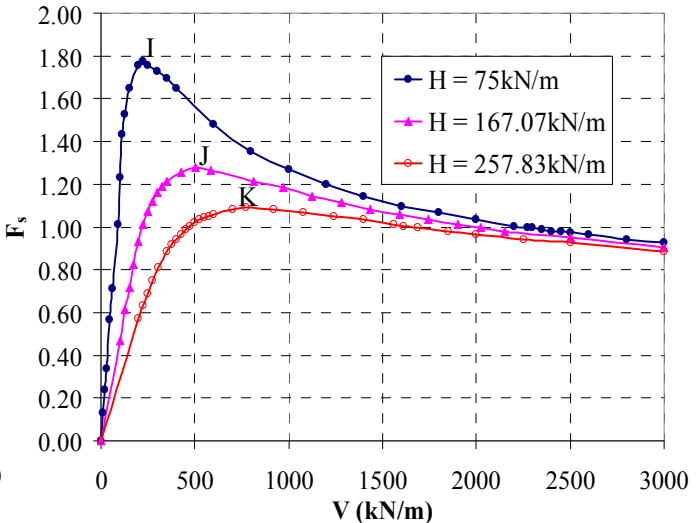

Figure 3: Safety factor $F_{s}$ versus $V$ for prescribed $H$ values

Figure (5) presents the effect of the vertical load $\mathrm{V}$ on the safety factor and the failure probability for the case of $\mathrm{H}=167.07 \mathrm{kN} / \mathrm{m}$. The case of normal uncorrelated variables is considered. The factor of safety first increases with the increase of $\mathrm{V}$ to reach a maximal value. Then, it decreases with the increase of V. However, the probability of failure first decreases then increases with the increase of V. Thus, contrary to the safety factor, the curve of the failure probability exhibits a minimum. It can be easily seen that the minimal value of the failure probability and the maximal value of the safety factor correspond exactly to the same value of $\mathrm{V}$ for a prescribed $\mathrm{H}$. These observations may be explained as follows: for small values of $\mathrm{V}$, the sliding failure mode of the foundation is predominant. This leads to a high failure probability. As V increases, the effect of the sliding mode decreases and that of the punching mode increases. For the value of $\mathrm{V}$ for which the safety factor is maximal and the failure probability is minimal, the contribution of the two modes of failure to the failure probability is minimal. This is because neither modes of failure is predominant in this case. Finally, notice that a further increase in $\mathrm{V}$ will lead to a predomination of the punching mode with respect to the sliding one. This in turn leads to a significant increase in the failure probability. Concerning the cost of calculations, the computational time for the determination of the safety factor (i.e. each point of the curves shown in figure (3)) was about $180 \mathrm{~min}$. using an Intel 2.40 $\mathrm{GHz}$ PC. For the reliability analysis, it is important to mention that only two iterations (i.e. a total of $2 \times 5=10$ deterministic model runs) were found necessary to achieve the convergence of the reliability index. Thus, each computation of $\mathrm{P}_{\mathrm{f}}$ in figure (5) has required about $10 \times 180=1800$ minutes which is very important. Notice however that this type of analysis involving the use of the safety factor defined with respect to the soil shear strength parameters has a great advantage in reliability 
analysis since it is a simple and effective way for simultaneously exploring the two failure modes (soil punching and footing sliding) of ULS using a single simulation. Thus, one does not need to compute two reliability indices and to perform an approximate system reliability calculation.

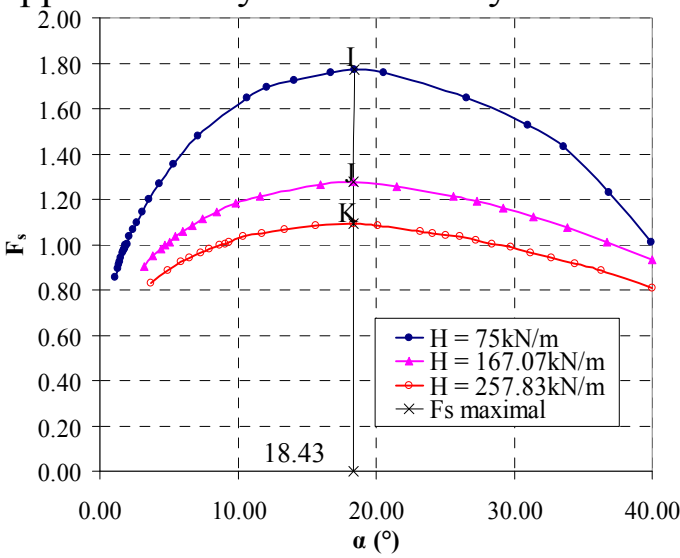

Figure 4: $F_{s}$ versus load inclination $\alpha$

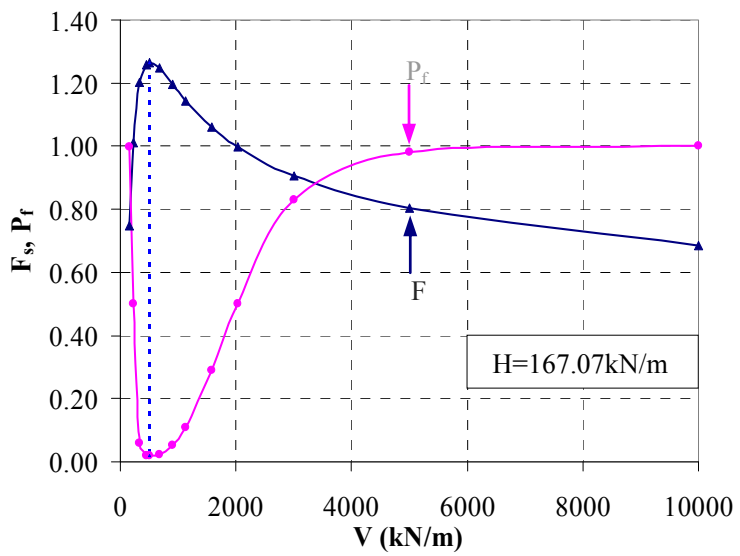

Figure 5: $F_{s}$ and $P_{f}$ versus $V$ for a prescribed $H$ value

Figure (6) presents the effect of (i) non-normality of the random variables and (ii) negative correlation between random variables, on the CDF of the safety factor for $\mathrm{V}=505 \mathrm{kN} / \mathrm{m}$ and $\mathrm{H}=167.07 \mathrm{kN} / \mathrm{m}$. By varying the target value «A» of $F_{\mathrm{s}}$, one can determine the $\mathrm{CDF}$ of $\mathrm{F}_{\mathrm{s}}$ for a given soil variability as follows:

$$
\operatorname{CDF}\left(\mathrm{F}_{\mathrm{s}}\right)=\mathrm{P}\left[\mathrm{F}_{\mathrm{s}} \leq \mathrm{A}\right]=\mathrm{P}_{\mathrm{f}}
$$

where $\mathrm{F}_{\mathrm{s}}$ is the safety factor calculated by $\mathrm{FLAC}^{3 \mathrm{D}} ; \mathrm{P}_{\mathrm{f}}$ is the failure probability obtained by FORM approximation using the value of the reliability index for $\mathrm{G}=\mathrm{F}_{\mathrm{s}}-\mathrm{A}$ where $A$ is the target value of $F_{s}$. It has to be noticed that $F_{s}$ is equal to 1.26 for the mean values of the random variables. The CDF is presented in a logarithmic scale in order to provide with a good accuracy the values of the failure probability in the tail region of the CDF. These regions are very important in practice since they correspond to the small failure probabilities which are generally adopted in engineering design. One can notice that the negative correlation between the shear strength parameters decreases the failure probability. However, the non-normality of the random variables has a minor effect on $\mathrm{P}_{\mathrm{f}}$.

Figure (7) presents the effect of $\mathrm{COV}_{c}$ and $\mathrm{COV}_{\varphi}$ on the CDF of the safety factor for $\mathrm{V}=505 \mathrm{kN} / \mathrm{m}$ and $\mathrm{H}=167.07 \mathrm{kN} / \mathrm{m}$. Three cases are presented: i) $\mathrm{COV}_{\mathrm{c}}=20 \%$ and $\mathrm{COV}_{\varphi}=10 \%$, ii) $\mathrm{COV}_{\mathrm{c}}=40 \%$ and $\mathrm{COV}_{\varphi}=10 \%$ and iii) $\mathrm{COV}_{\mathrm{c}}=20 \%$ and $\mathrm{COV}_{\varphi}=15 \%$. The case of non-normal and correlated variables is considered. One can observe that a small variation in $\mathrm{COV}_{\varphi}$ highly affect the $\mathrm{CDF}$ of $\mathrm{F}_{s}$. Thus, the accurate determination of the uncertainties of the angle of internal friction $\varphi$ is very important in obtaining reliable probabilistic results. 


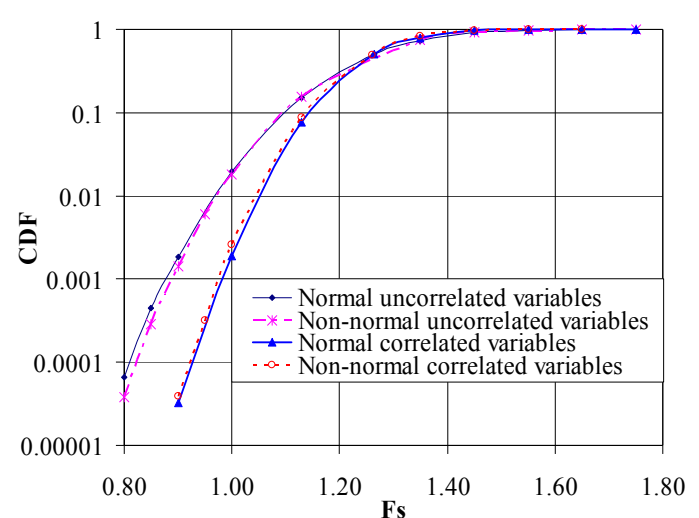

Figure 6: Effect of $\rho_{c, \varphi}$ and probability distribution on the CDF of $F_{s}$

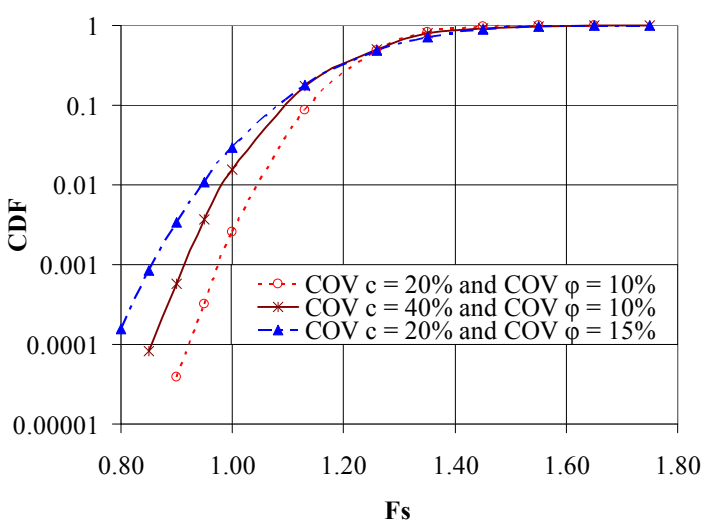

Figure 7: Effect of $\mathrm{COV}_{\mathrm{c}}$ and $\mathrm{COV}_{\varphi}$ on the CDF of $\mathrm{F}_{\mathrm{s}}$

\section{Eccentric loading case}

The results of the eccentric loading case are presented in the form of an interaction diagram $(\mathrm{M}, \mathrm{V})$ (which corresponds to $\mathrm{F}_{\mathrm{s}}=1$ ) using the mean values of the shear strength parameters $c$ and $\varphi$ (figure (8)). For small values of the vertical load component V (i.e. high load eccentricities), overturning failure mode of the foundation occurs. This leads to separation between footing and soil. However, for high values of $\mathrm{V}$ (i.e. small load eccentricities), soil punching is developed. For intermediate $\mathrm{V}$ values, a transition from punching failure mode to the overturning failure mode occurs. Similarly to the case of the inclined load, the safety factor defined with respect to the soil shear strength parameters is adopted herein.

Figure (9) presents the variation of the safety factor $F_{s}$ with the vertical load $V$ for the three loading cases shown in Figure (8) and corresponding to prescribed $M$ values. For the different values of $\mathrm{M}$, one can notice that the maximal safety factor corresponds to the same ratio of $\mathrm{M} / \mathrm{V}$ (i.e. to the same load eccentricity). In order to interpret this result, the factor of safety is plotted versus the load eccentricity e in figure (10). From this figure, one can observe that the factor of safety reaches its maximal value at the same eccentricity $(e=0.5$ i.e. $e / B=1 / 4$ in the present case) for different values of $\mathrm{M}$. This observation is similar to that found in the inclined load case and will be explained below.

Figure (11) presents the effect of the vertical load component V on the safety factor and the failure probability, for the case of $\mathrm{M}=324.05 \mathrm{kNm} / \mathrm{m}$ shown in figure (10). The case of normal uncorrelated variables is adopted in this figure. As in the inclined load case, it can be easily seen that the minimal value of the failure probability and the maximal value of the safety factor correspond exactly to the same value of $\mathrm{V}$ (for a prescribed $\mathrm{M}$ ). This observation may be explained as follows: for small values of $\mathrm{V}$, the overturning failure mode of the foundation is predominant. This leads to a high failure probability. As $\mathrm{V}$ increases, the effect of the overturning mode decreases and that of the punching mode increases. For the value of $\mathrm{V}$ for which the safety factor is maximal and the failure probability is minimal, the contribution of the two modes of failure to the failure probability is minimal. This is because neither modes of failure is predominant in this case. Beyond this particular value of $\mathrm{V}$, an increase in $\mathrm{V}$ will lead to a predomination of the punching mode with 
respect to the overturning one and thus to a significant increase in the failure probability. Finally, it should be noted here that separation along the soil-footing interface has occurred for several values of the load eccentricities including the one corresponding to the minimal probability.
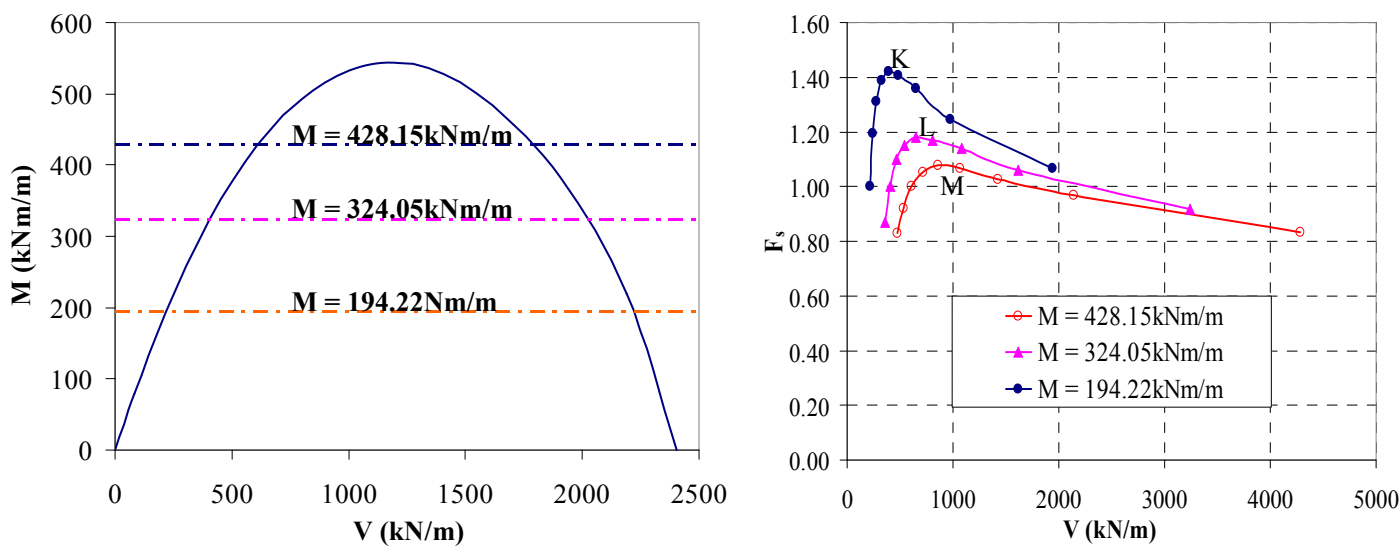

Figure 8: Interaction diagram (M, V)

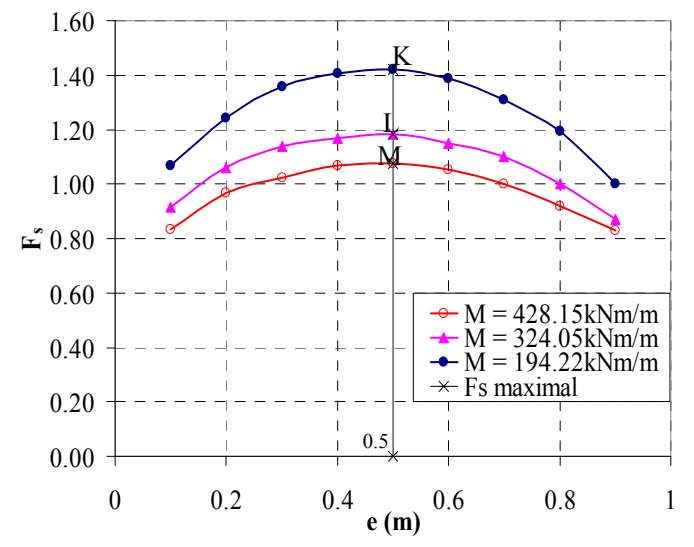

Figure 10: $F_{s}$ versus load eccentricity e
Figure 9: Safety factor $F_{s}$ versus $V$ for prescribed $M$ values

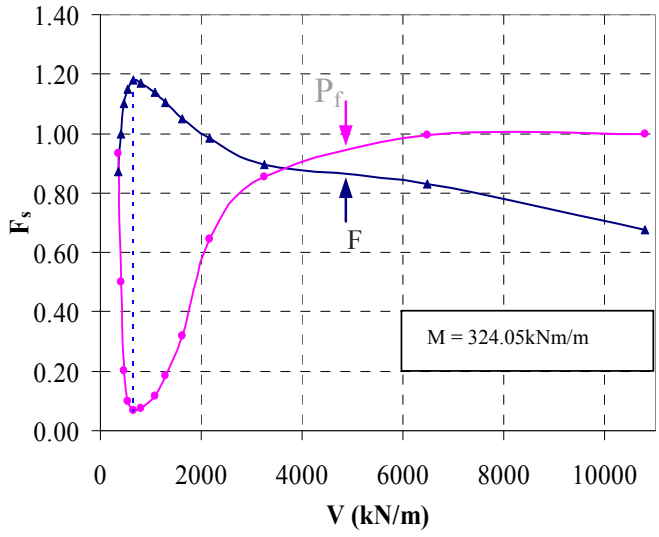

Figure 11: $F_{s}$ and $P_{f}$ versus $V$ for a prescribed $M$ value

\section{CONCLUSION}

A reliability-based approach for the analysis of a shallow strip footing resting on a frictional and cohesive soil and subjected to an inclined or an eccentric loading was presented. The cohesion and the angle of internal friction were considered as random variables. The Hasofer-Lind reliability index was used for the computation of the footing reliability. The response surface methodology was employed for the assessment of the reliability index. The performance function adopted in the analysis made use of the safety factor defined with respect to the soil shear strength parameters $c$ and $\tan \varphi$. This safety factor was determined using the finite difference code FLAC $^{3 \mathrm{D}}$. It was shown that for a given soil, there is a load inclination for which the two failure modes involved by the loading case are not predominant. For the load configurations corresponding to this load inclination, the safety factor is maximal and the failure probability is minimal with respect to all other load configurations having the same value of the horizontal load component $\mathrm{H}$. Similar results were obtained in 
the case of an eccentric loading: there is an eccentricity for which the factor of safety is maximal and the failure probability is minimal with respect to all other load configurations having the same value of M. Finally, it was shown that the hypothesis of negative correlation between random variables increases the reliability of the footing and that the failure probability is very sensitive to the variation of the angle of internal friction compared to that of the cohesion.

\section{REFERENCES}

Bauer, J., and Pula, W. (2000). "Reliability with respect to settlement limit-states of shallow foundations on linearly deformable subsoil." Computers \& Geotechnics, 26, 281-308.

Cherubini, C. (2000). "Reliability evaluation of shallow foundation bearing capacity on c', $\varphi$ ' soils." Can. Geotech. J., 37, 264-269.

Fenton, G.A., and Griffiths, D.V. (2003). "Bearing capacity prediction of spatially random c- $\varphi$ soils." Canadian Geotechnical Journal, 40, 54-65.

Hasofer, A. M., and Lind, N. C. (1974). "Exact and invariant second-moment code format." Journal of Engineering Mechanics, ASCE, 100(1), 111-121.

Low, B. K., and Phoon, K. K. (2002). "Practical first-order reliability computations using spreadsheet." Probabilistics in Geotechnics: Technical and Economic Risk Estimation, Austria, 39-46.

Lumb, P. (1970). "Safety factors and the probability distribution of soil strength." Can. Geotech. J., 7, 225-242.

Phoon, K.-K., and Kulhawy, F. H. (1999). "Evaluation of geotechnical property variability." Can. Geotech. J., 36, 625-639.

Popescu, R., Deodatis, G., and Nobahar, A. (2005). "Effects of random heterogeneity of soil properties on bearing capacity." Probabilistic Engineering Mechanics, 20, 324-341.

Soubra, A.-H., and Youssef Abdel Massih, D.S. (2009). "Probabilistic analysis and design at the ultimate limit state of obliquely loaded strip footings." Géotechnique, ICE, accepted, in press.

Tandjiria, V., Teh, C.I, and Low, B.K. (2000). "Reliability analysis of laterally loaded piles using response surface method." Structural Safety, 22, 335-355.

Wolff, T. H. (1985). "Analysis and design of embankment dam slopes: A probabilistic approach.” Ph.D. thesis, Purdue Univ., Lafayette, Ind.

Youssef Abdel Massih, D. and Soubra A.-H. (2007). "Numerical simulations for the bearing capacity of strip footings". Geo-Denver 2007, ASCE, Denver, USA, 18-21 February, 10 pages.

Youssef Abdel Massih, D.S., and Soubra, A.-H. (2008). "Reliability-based analysis of strip footings using response surface methodology." International Journal of Geomechanics, ASCE, 8(2), 134-143.

Youssef Abdel Massih, D.S., Soubra, A.-H., and Low, B.K. (2008). "Reliabilitybased analysis and design of strip footings against bearing capacity failure." $J$. of Geotech. \& Geoenv. Engrg., ASCE, 134(7), 917-928.

Yuceman, M. S., Tang, W. H., and Ang, A. H. S. (1973). "A probabilistic study of safety and design of earth slopes." Civil engineering studies, Structural Research Series 402, University of Illinois Press, Urbana, Ill. 